\title{
Outbreak of acute Chagas disease associated with oral transmission in the Rio Negro region, Brazilian Amazon
}

\author{
Rita de Cássia de Souza-Lima ${ }^{[1]}$, Maria das Graças Vale Barbosa ${ }^{[1],[2],[3],}$ \\ José Rodrigues Coura ${ }^{[4]}$, Ana Ruth Lima Arcanjo ${ }^{[1],[4]}$, Adelaide da Silva Nascimento ${ }^{[4]}$, \\ João Marcos Bemfica Barbosa Ferreira ${ }^{[5]}$, Laylah Kelre Magalhães ${ }^{[2],}$ \\ Bernardino Cláudio de Albuquerque ${ }^{[1],[6]}$, Guilherme Alfredo Novelino Araújjo ${ }^{[7]}$ \\ and Jorge Augusto de Oliveira Guerra ${ }^{[1],[2]}$
}

[1]. Gerência de Leishmaniose e Gerencia de Entomologia, Fundação de Medicina Tropical Dr. Heitor Vieira Dourado, Manaus, AM. [2]. Escola Superior de Ciências da Saúde, Programa de Pós-Graduação em Medicina Tropical, Universidade do Estado do Amazonas, Manaus, AM. [3]. Pró-Reitoria de Pesquisa e Pós-graduação, Universidade Nilton Lins, Manaus, AM. [4]. Instituto Oswaldo Cruz, Fundação Oswaldo Cruz, Rio de Janeiro, RJ. [5]. Hospital Universitário Francisca Mendes, Universidade Federal do Amazonas, Manaus, AM. [6]. Departamento Vigilância Epidemiológica, Fundação de Vigilância em Saúde do Amazonas, Manaus, AM. [7]. Laboratório Central de Saúde, Fundação de Vigilância em Saúde do Amazonas, Manaus, AM.

\begin{abstract}
Introduction: Chagas disease is considered as emerging in the Brazilian Amazon, usually occurring in acute outbreaks. Methods: We describe 17 cases of acute Chagas disease in Rio Negro, Amazonas. Results: There were 15 males (average age, 31.3 years), all positive for Trypanosoma cruzi in fresh blood smear examination, and 14 positive by xenodiagnosis and PCR. The top clinical manifestations were fever, asthenia, abdominal pain, and palpitations. Electrocardiograms featured low-voltage QRS, anterosuperior divisional block, and right bundle branch block associated with anterosuperior divisional block. Conclusions: All patients had consumed açaí products from Monte Alegre in the rural area around Santa Izabel do Rio Negro, Brazil.
\end{abstract}

Keywords: Chagas disease. Acute outbreak. State of Amazonas.

Several outbreaks of acute Chagas disease in the Amazon region ${ }^{1}$ have been associated with oral consumption of açaí. The most accepted transmission mechanism is contamination due to triatomine feces in the fruit or by insects that are inadvertently crushed while the fruit is being processed. In this process, Trypanosoma cruzi can remain viable, especially if the juice is not subjected to pasteurization, but not through rapid freezing ${ }^{2,3}$. There were outbreaks of acute Chagas disease in 2004 in the municipality of Tefé ${ }^{4}$ and in 2008 in Coari ${ }^{5}$, both with the suspicion of oral transmission via açaí juice. The objective of this study was to describe the epidemiological, clinical, and laboratory characteristics of an outbreak of acute Chagas disease associated with oral transmission that occurred in January 2010 in a region along the Rio Negro around Santa Isabel do Rio Negro (SIRN) in the State of Amazonas, Brazil (coordinates $00^{\circ} 24^{\prime} 50^{\prime \prime} \mathrm{S} \mathrm{65} 05^{\circ} 08^{\prime \prime} \mathrm{W}$ ) (Figure 1) ${ }^{6}$.

On January 4, 2010, the local diagnostic service for malaria detected trypomastigote forms of T. cruzi in the peripheral blood of a 69-year-old retired smallholder (index case) who lived in the municipality of SIRN. This individual presented with a 9-day

Address to: Dr. Jorge Augusto de Oliveira Guerra. Gerência de Leishmaniose/ FMT-HVD. Av. Pedro Teixeira 25, D. Pedro, 69040-000 Manaus, AM, Brasil. Phone: 5592 2127-3555; 5592 2127-3516

e-mail: jguerra291@gmail.com

Received 21 September 2011

Accepted 11 November 2011 history of fever, asthenia, abdominal pain, and palpitations. At the same time, another 3 cases with similar symptoms were diagnosed in the patient's family. Another 10 cases were identified concomitantly. All of the patients had in common a history of consumption of açaí juice originating from a batch that came from the riverside community of Monte Alegre, in the rural zone of SIRN, that had been produced from raw fruit harvested from a single tree on December 15, 2009. The index case and the 3 members of his family consumed manually prepared juice in their own home on December 18, 2009. The juice consumed by the other patients had been prepared manually in the Monte Alegre community (MAC) and was consumed on the same day, December 16, 2009, aboard the Mano Zeca, a local fishing/ tourism boat.

After the local authorities raised the alert, a team of technical experts from the Fundação de Vigilância em Saúde (FVS), the Laboratório Central (LACEN), and the Fundação de Medicina Tropical Dr. Heitor Vieira Dourado (FMT-HDV) was formed, and the team went to the affected municipality with the aim of evaluating the situation and controlling the outbreak. The actions undertaken are described in the flowchart (Figure 2).

The cases were classified as suspected or confirmed in accordance with the Brazilian Consensus for Chagas Disease? Suspected cases included individuals who consumed açaí originating from MAC, prepared from a batch with suspicion of T. cruzi contamination, and consumed between December 16 and 18, 2009. Confirmed cases included individuals who 


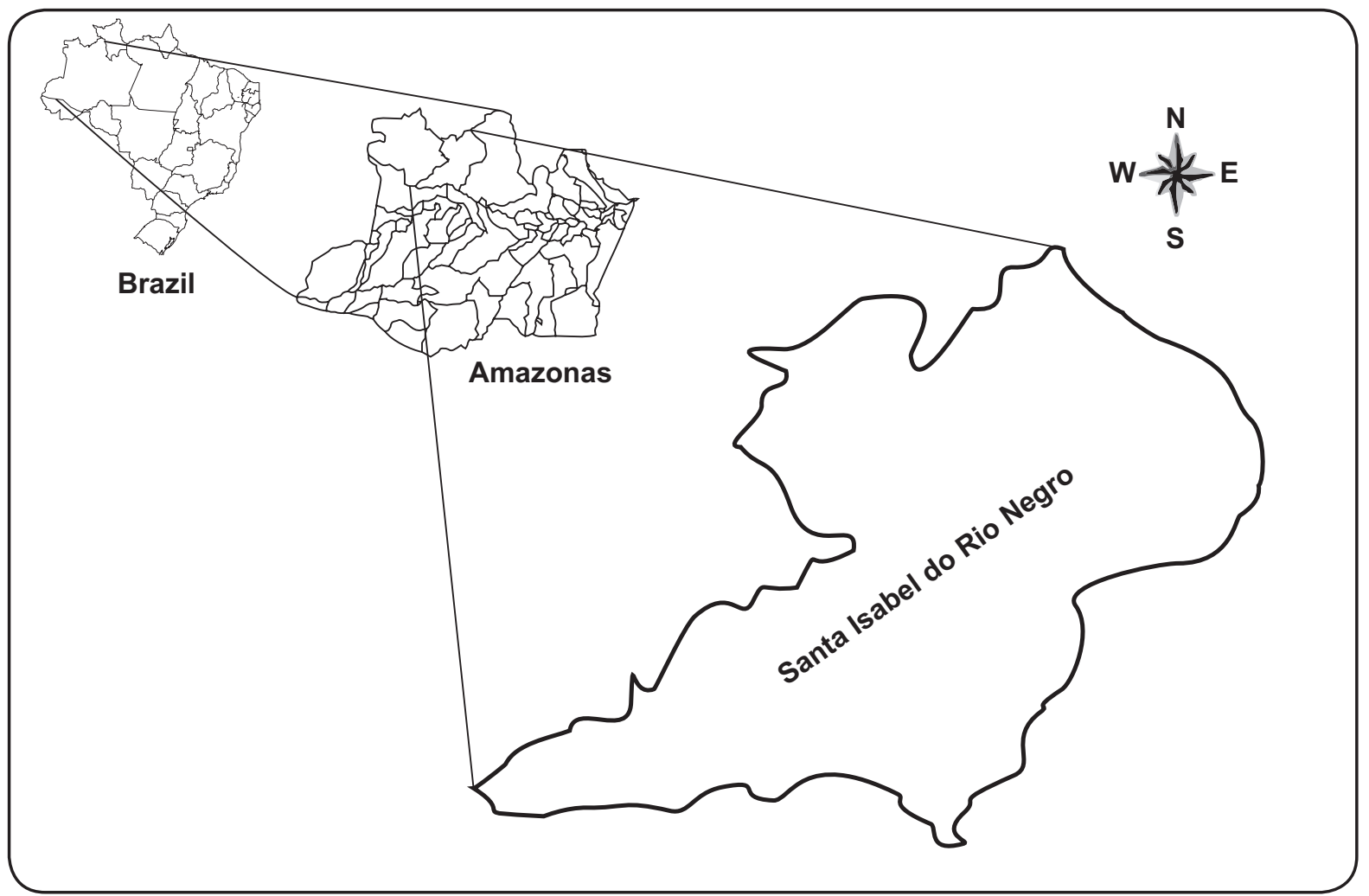

FIGURE 1 - Municipality of Santa Isabel do Rio Negro, State of Amazonas, Brazil.

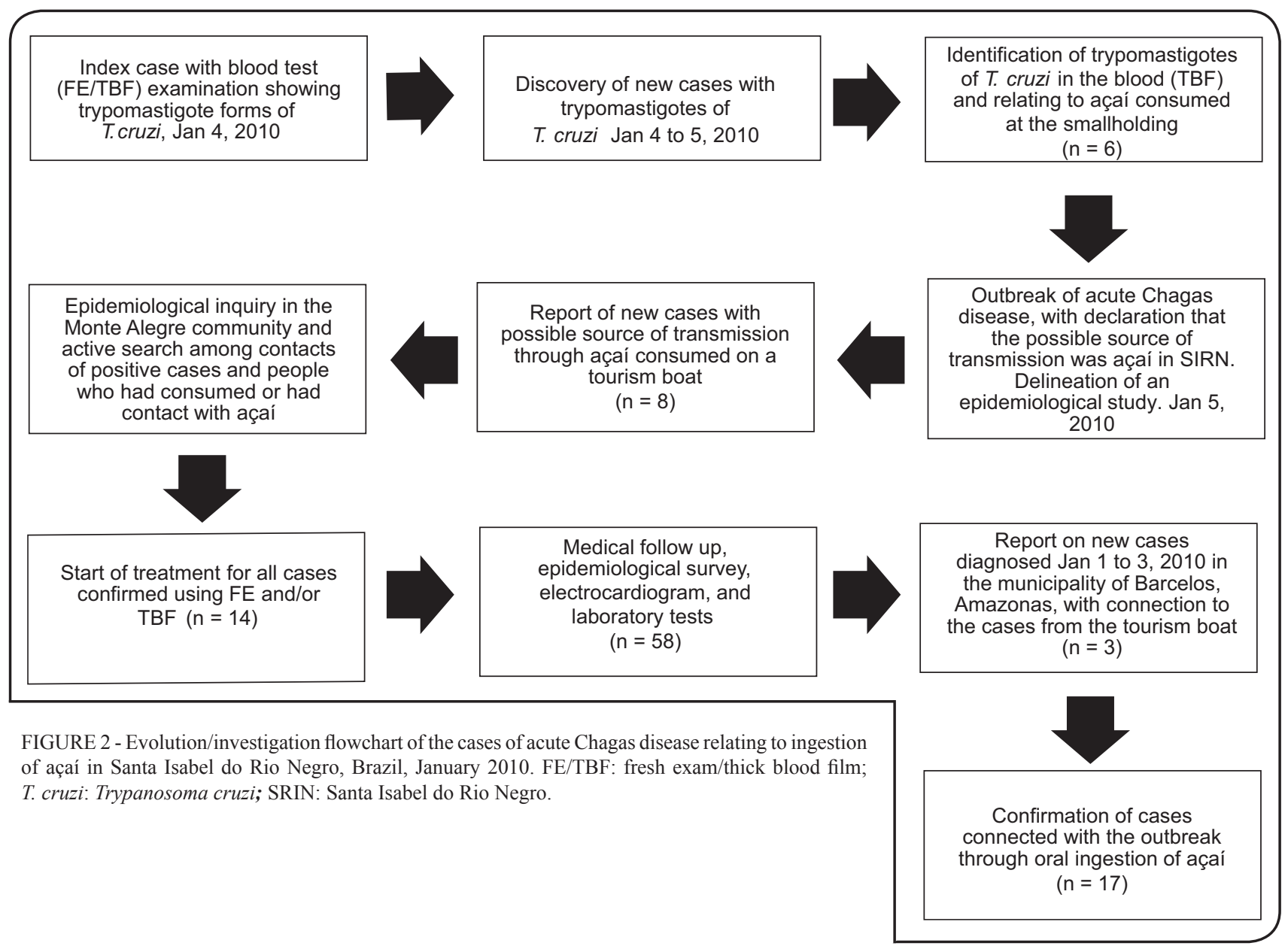


consumed the suspected food with or without presentation of symptoms but with the presence of trypomastigote forms of T. cruzi in peripheral blood when other means of transmission were considered unlikely.

A total of 58 individuals were evaluated, and all them had been involved in the preparation or transportation of the açaí consumed on the Mano Zeca boat and in the home of the index case. There were 28 individuals were from the MAC and 30 from the urban area of the municipality of SIRN.

Blood samples for the diagnosis were initially gathered from January 7 to 9, 2010. The investigation method used was a seroepidemiological inquiry for which the tools included an interview form (to gather epidemiological data), a clinical examination, collection of biological specimens for serological testing, and the following laboratory tests: thick blood smear, complete blood count, hemagglutination (HE), indirect immunofluorescence (RIFI), enzyme-linked immunoabsorbent assay (ELISA), polymerase chain reaction (PCR), electrocardiogram (EKG), and chest radiography. Venous blood samples were taken for diagnosis, and aliquots were drawn for fresh examination, thick blood smear, seeding in culture medium, with serum for RIFI, ELISA, and HE tests, as recommended by ${ }^{7}$ the Ministry of Health, Brazil.

Initially, 14 cases of acute Chagas disease were identified based on the evaluation of 58 individuals in the central area of the SIRN municipality and in the riverside community of Monte Alegre.

Weekly control slides were produced over a 1-month period as follow-up for the treatment or to detect new cases among the individuals who had consumed or had been in contact with the acai, and all 14 patients evaluated were $T$. cruzi positive by PCR and xenodiagnosis.

To correlate the suspected food to the outbreak, the attack rate among these 14 patients was calculated. The results from these calculations showed that the food most commonly consumed among the people who fell ill was açaí with manioc flour (85\%). Five patients from the Mano Zeca who consumed açai were in the municipality of Barcelos during the onset of symptoms, and these patients were diagnosed in the municipality on 1 and 3 January 2010. Two of these patients returned to SIRN for treatment because all medication available in Barcelos had been sent to SIRN for the treatment of the diagnosed cases in the outbreak. These patients underwent new thick blood exams and fresh blood examination, from which they were confirmed positive for T. cruzi and were then listed among the 14 cases originally detected during the investigation carried out in SIRN. The other 3, who were diagnosed later in Barcelos waited for medicine, and for that reason they were linked to the outbreak later. Nevertheless, there was a strong epidemiological connection, i.e., the appearance of symptoms and time of diagnosis coincided with the other cases presented in this study.

Data available after the investigation that was subsequently conducted in Barcelos for the 3 cases notified and treated in Barcelos are presented here. Thus, it was concluded that there were 17 cases recorded from this outbreak (Table 1). The cases were predominantly in men, who accounted for $88.2 \%$ (15) of the cases, with an age range from 10 to 70 years and a mean age of 30.7 years.

All patients denied receiving blood transfusions or organ transplants or having consumed meat during the period. One patient reported having slept near Barcelos (Bela Vista smallholding) on December 23, 2009, and seeing triatomine insects there. However, no cases of Chagas disease are known among the people who live there. Another patient reported having slept in a rural area 3 months earlier, in the Castanheira community (camping in the middle of the forest, where he spent the night), but he said he had not seen any triatomines on that occasion. However, he reported that he had seen triatomines 3 months prior to the outbreak in among the buriti trees in the MAC.

The 14 patients initially diagnosed in SIRN underwent electrocardiograms while at rest on January 23, 2010. Alterations were found in 3 patients (21.4\%). There was 1 case of low frontal plane QRS voltage, 1 of an isolated anterosuperior divisional block (ASDB), and 1 of a right bundle branch block (RBBB) associated with an isolated anterosuperior divisional block. Eleven (78.6\%) patients had normal EKGs. The patient with the EKG showing RBBB associated with ASDB traveled to Manaus and was evaluated at a cardiology clinic on May 31,2010. He was asymptomatic from a cardiovascular point of view, with a normal cardiac examination and transthoracic echocardiogram, while his EKG maintained the pattern of RBBB with ASDB. No EKG was performed on any of the 3 patients diagnosed in Barcelos.

This is the first report of an outbreak with these characteristics in the Rio Negro region. However, from an epidemiological perspective, Chagas disease has been occurring in this area for several years. It is even considered to be an occupational disease, because it is related to the extraction of piaçaba, during which individuals come into contact with Rhodnius brethesi, a known vector of the disease in that area, particularly in Barcelos, the municipality neighboring SIRN ${ }^{8-11}$.

The clinical data in the present study were in agreement with what has been reported previously in the literature regarding cases associated with oral transmission. In these cases, symptoms not normally associated with acute cases relating to vector transmission are highlighted, such as absence of entry signs, abdominal pain, diarrhea, generalized and facial edema, or the presence of skin rash ${ }^{1}$, which, however, was not observed during the present series, in which fever syndrome with a sudden onset was the most frequent clinical presentation, accompanied by myalgia and asthenia, as has been reported in endemic areas. This was reported in $100 \%$ of the acute cases described ${ }^{1,12}$.

The frequency of electrocardiographic abnormalities found in this outbreak (21.4\%) was lower than the frequencies found previously by other authors. Pinto et al. ${ }^{8}$ reported that $51.1 \%$ of the electrocardiograms in a series of 233 acute cases in the States of Pará, Maranhão, and Amapá showed abnormalities. Ferreira et al. ${ }^{13}$ found that in 6 cases of acute Chagas disease seen at FMT-HVD, 83.3\% had electrocardiogram abnormalities common among patients with acute Chagas disease ${ }^{1,14}$, including low QRS voltage, isolated ASDB, and, especially, RBBB associated with ASDB. 
TABLE 1 - Outbreak of acute Chagas disease in the municipality of Santa Izabel do Rio Negro. Summary of the cases according to age, gender, and laboratory results

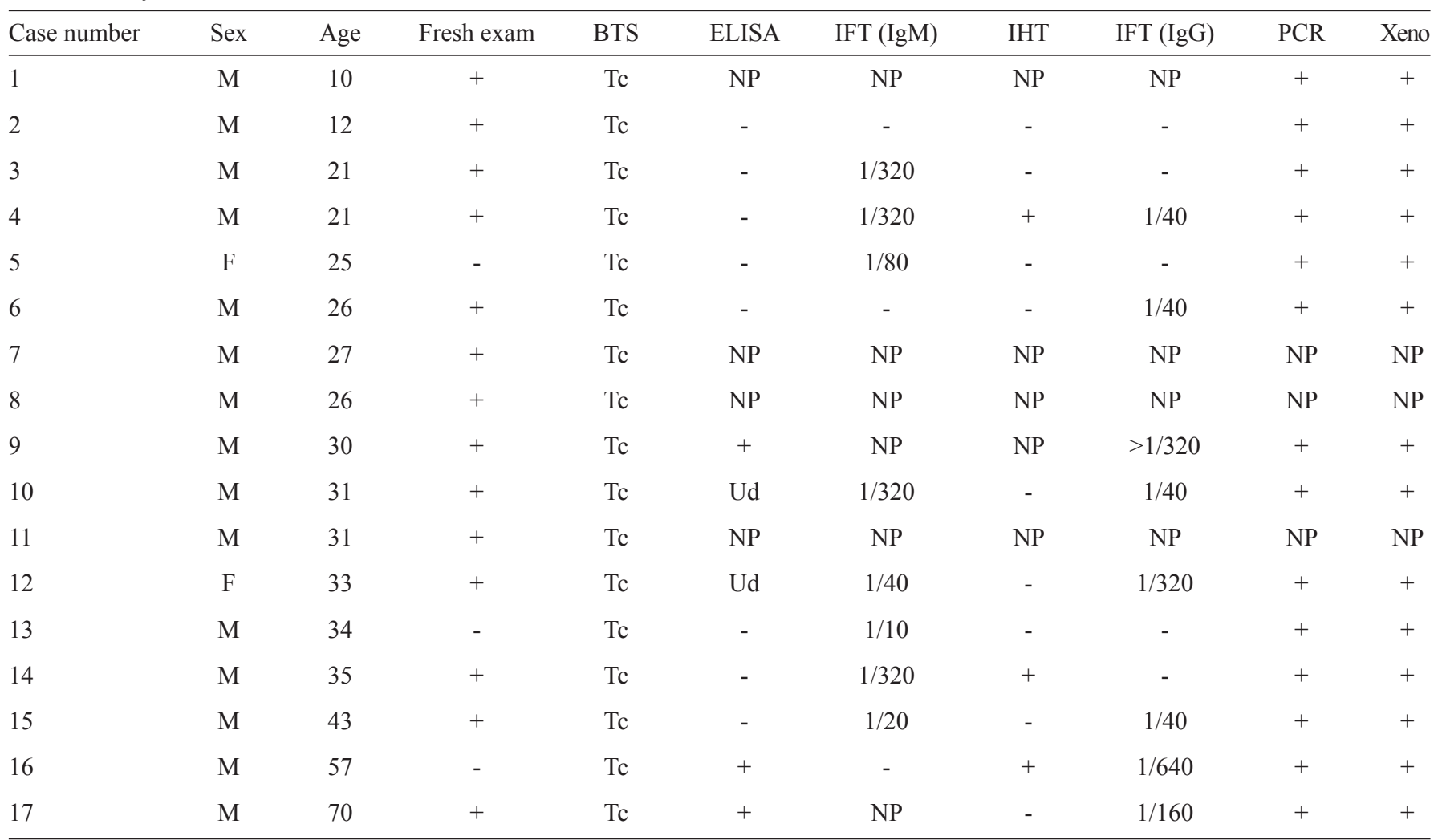

BTS: blood thick smear; ELISA: enzyme-linked immunosorbent assay; IFT (IgM): indirect immunofluorescence test for immunoglobulin M; IHT: indirect hemagglutination test; IFT (IgG): indirect immunofluorescence test for immunoglobulin G; PCR: polymerase chain reaction; xeno: xenodiagnosis; M: male; F: female; +: positive; -: negative; Tc: Trypanosoma cruzi; NP: not performed; Ud: undetermined.

Some studies in the Amazon region have suggested that morbidity associated with the chronic phase of Chagas disease is low, possibly due to low levels of parasitemia or to the characteristics of the circulating strains. In the municipality of Barcelos, prevalence has been estimated to be between $2.8 \%$ and $5 \%{ }^{1,3}$, due especially to the large portion of the population in the region that comes into contact with the $R$. brethesi vector during the extraction of piaçava ${ }^{11,14}$, and there are occurrences of patients in this municipality with dilated cardiomyopathy. Fatal cases of Chagas disease have also been confirmed, and the data suggest that there is now a significant circulation of the disease in the Rio Negro region, with acute and chronic cases occurring in the municipalities that make up this region ${ }^{9,10}$. This can be corroborated by the situation that occurred during the investigation of the outbreak in SIRN, in which the cases of 3 patients not initially associated with the outbreak called attention to the movement of cases within the region, as has also been demonstrated by other authors ${ }^{1,9,11,13,14}$.

The occurrence of this outbreak again reinforces the need to establish an algorithm for integrated medical assistance in this region. The 5 cases with a strong epidemiological link that were initially diagnosed in Barcelos, with 2 confirmations in SIRN, were similar to an acute Chagas disease outbreak that occurred in
Santarem in 2006, in which 2 cases were diagnosed in Manaus. This served as an alert for an outbreak with suspected oral transmission. Another 18 cases were then diagnosed as a result of the investigation made in Santarem, to which the 2 diagnoses in Manaus were added. Delayed diagnosis among the Santarem cases resulted in 1 death in Santarem before the outbreak had been confirmed.

The emergence and expansion of endemic Chagas disease in the Amazon region is related to complex ecological and social dynamics. The Amazon region is currently inhabited by more than 30 million people who interact within the process of occupying the region. Active participation by a network of malaria diagnosis laboratories in investigation of acute cases of Chagas disease through capacitation and systemic supervision of field laboratory technicians who perform blood tests has been a fundamental strategy and must be maintained. In this manner, a standardized protocol for clinical evaluation and characterization of these cases can be established, not only for those cases in which isolated feverish patients are detected (i.e., malaria slides), but also for those detected in family episodes. Establishment and maintenance of a preventive surveillance system, with the capacity to diagnose and treat autochthonous and imported cases, may avoid dispersion and intensification of endemic transmission of Chagas disease in the Amazon ${ }^{15}$. 


\section{CONFLICT OF INTEREST}

The authors declare that there is no conflict of interest.

\section{FINANCIAL SUPPORT}

This research was supported by the Fundação de Medicina Tropical Dr. Heitor Vieira Dourado (FMT-HVD) and the Fundação de Vigilância em Saúde.

\section{REFERENCES}

1. Pinto AY, Valente SA, Valente VC, Ferreira Junior AG, Coura JR. Acute phase of Chagas disease in the Brazilian Amazon region: study of 233 cases from Para, Amapá and Maranhão observed between 1988 and 2005. Rev Soc Bras Med Trop 2008; 41:602-614.

2. Nóbrega AA, Garcia MH, Tatto E, Obara MT, Costa E, Sobel J, et al. Oral transmission of Chagas disease by consumption of acaí palm fruit, Brazil. Emerg Infect Dis 2009; 15:653-655.

3. Ministério da Saúde. Doença de Chagas aguda por transmissão oral [Internet]. Brasília: Ministério da Saúde; 2007 [Cited 2010 Jul 30]. Available from: http:// portal.saude.gov.br/portal/arquivos/pdf/nota_chagas2308.pdf/.

4. Medeiros MB, Guerra JAO, Lacerda MVG. Meningoencefalite em paciente com doença de Chagas aguda na Amazônia Brasileira. Rev Soc Bras Med Trop 2008; 41:520-521.

5. Barbosa-Ferreira JM, Guerra JAO, Santana FS, Magalhâes BML, Coelho LIARC, Barbosa MGV. Acometimento cardíaco em Doença de Chagas aguda da Amazônia. Arq Bras Cardiol 2010; 94:147-149.
6. Instituto Brasileiro de Geografia e Estatística (IBGE). Censo demográfico [Internet]. Brasília: IBGE; 2004 [Cited 2009 August 22]. Available from: http:// www.ibge.gov.br/home/.

7. Ministério da Saúde. Consenso Brasileiro em Doença de Chagas. Rev Soc Bras Med Trop 2005; 38 (supl III):1-29.

8. Brum-Soares LM, Xavier SS, Sousa AS, Borges-Pereira J, Ferreira JM, Costa IR, et al. Morbidity of Chagas disease among autochthonous patients from the Rio Negro microregion, State of Amazonas. Rev Soc Bras Med Trop 2010; 43:170-177.

9. Xavier SS, Sousa AS, Vinas PA, Junqueira AC, Boia MN, Coura JR. Chronic chagasic cardiopathy in the Rio Negro, Amazon State. Report of three new autochthonous cases confirmed by serology, clinical examination, chest X-rays, electro and echocardiography. Rev Soc Bras Med Trop 2006; 39:211-216.

10. Vinas-Albajar P, Laredo SV, Terrazas MB, Coura JR. Dilated cardiomyopathy in patients with chronic chagasic infection: report of two fatal autochthonous cases from Rio Negro, State of Amazonas, Brazil. Rev Soc Bras Med Trop 2003, 36:401-407.

11. Coura JR, Junqueira AC, Giordano CM, Funatsu RK. Chagas' disease in the Brazilian Amazon. I- A short review. Rev Inst Med Trop Sao Paulo 1994; 36:363-368.

12. Dias JCP. Doença de Chagas em Bambuí, Minas Gerais, Brasil. Estudoepidemiológico a partir da fase aguda, ente 1940 a 1982. [Doctors Thesis]. [Belo Horizonte]: Universidade Federal de Minas Gerais; 1982.

13. Ferreira JMBB, Guerra JAO, Barbosa MGV. Ventricular aneurysm in a chronic Chagas disease patient from the Brazilian Amazon region. Rev Soc Bras Med Trop 2009; 42:474-475.

14. Coura JR, Junqueira AC, Fernandes O, Valente SA, Miles MA. Emerging Chagas disease in Amazonian Brazil. Trends Parasitol 2002, 18:171-176.

15. Aguilar HM, Abad-Franch F, Dias JC, Junqueira AC, Coura JR. Chagas disease in the Amazon region. Mem Inst Oswaldo Cruz 2007; 102 (supl I):47-56. 